\title{
Neoadjuvant Treatment of Breast Cancer
}

\author{
Michael Untch $^{\mathrm{a}}$ Gunter von Minckwitz ${ }^{\mathrm{b}}$ \\ ${ }^{a}$ Klinik für Gynäkologie und Geburtshilfe, HELIOS Klinikum Berlin-Buch, \\ ${ }^{b} \mathrm{GBG}$ Forschungs $\mathrm{GmbH}$, Neu-Isenburg, Germany
}

This is an ideal moment to present a special issue of Breast Care with focus on neoadjuvant therapy. After a successful cooperation of the German Neoadjuvant Study Groups of AGO-B and GBG with major publications in The Journal of National Cancer Institute, Journal of Clinical Oncology, Annals of Oncology, and Lancet Oncology, we are proud to have the results of the newest study - the GEPARQuinto accepted for publication in the New England Journal of Medicine. Second, the yearly San Antonio Breast Cancer Meeting has just finished and our study groups participated with a significant number of oral presentations and poster discussions. This is the result of a fruitful and successful year of clinical and translational study work. With the article by Jens Huober from St. Gallen, Switzerland, 'Neoadjuvant Therapy - what Have We Achieved in the Last 20 Years?' and the article by Guenther Steger and Rupert Bartsch from Vienna, Austria, about 'Trends and Novel Approaches in Neoadjuvant Treatment of Breast Cancer' we tried to give a perspective on this very important therapeutic approach for our breast cancer patients.

Jens Huober gives us an overview of the randomized trials comparing neoadjuvant and adjuvant treatment in operable breast cancer. We have learned that the indication for neoadjuvant therapy is no longer restricted to patients with large or inflammatory breast tumors, but also driven by the same criteria as adjuvant therapy. Of course, we have to acknowledge the pioneering work of our cooperative study groups in the NSABP and from M. D. Anderson, Houston, TX, but also the pivotal work done in Italy, France, UK, and Germany. The success story of neoadjuvant therapy is also a success story of the new chemotherapeutic regimens, such as anthracyclines, taxanes, dose dense therapy, and targeted therapy. It is obvious that in the multidisciplinary team involved in neoadjuvant treatment we need specialists and standardized procedures in imaging, pathologic assessment, systemic therapy including chemotherapy, antibody therapy, or targeted therapies, endocrine therapy, and radiation therapy. Jens Huober gives us not just an historic overview but summarizes the major results of international cooperative study groups with major achievements for the patients: more breast conserving surgery, better survival, better quality of life, and advancement of science.

The article by Guenther Steger and Rupert Bartsch focuses not only on the clinical aspects but also on the biology of breast cancer and possible approaches to target biology by using neoadjuvant systemic therapy. A large part of this article is dedicated to modern treatment approaches, such as antibody therapy, receptor tyrosine kinase inhibitors, VEGF directed therapy, and other targets like BRCA1 mutated tumors.

Both articles together are a very good mirror of the change in treatment approaches for breast cancer patients: neoadjuvant therapy is not just a research tool, but it is here to stay and to help our breast cancer patients.

\section{KARGER \\ Fax +497614520714 \\ Information@Karger.de}

www.karger.com (c) 2011 S. Karger GmbH, Freiburg

1661-3791/11/0066-0417\$38.00/0

Accessible online at:

www.karger.com/brc
Prof. Dr. med. Michael Untch

HELIOS Klinikum Berlin-Buch

Klinik für Gynäkologie und Geburtshilfe

Schwanebecker Chaussee 50, 13125 Berlin, Germany

Tel. +49 30 9401-53300, Fax -53309

michael.untch@helios-kliniken.de 